\title{
Studies on Heat Resistance of Conidiospores of
} Aspergillus fumigatus

\section{Qualitative Observation of the Resistance}

\author{
Tohru TSUKAHARA \\ Laboratory of Nutrition and Microbiology, Niigata Women's College, Niigata, Japan
}

\section{INTRODUGTION}

As generally known, the majority of fungus spcres of various types has no ability to survive thermal treatments which destroy the vegetative hyphae from which they arise. In early studies of the heat resistance, however, a certain type of fungal spores, i.e., ascospores of some Neurospora species were found resistant to heating at $50-60^{\circ} \mathrm{C}$ for more than 4 hours ${ }^{1) 2}$. A higher susceptibility of conidia of Neurospora tetrasperma to injury by heat was also observed in the latter investigation.

The present study deals with the changes in the heat resistance of conidiospores of Aspergillus fumigatus, which is best known as one of the thermophilic fungi, during maturation and germination and various factors which may affect their heat resistance.

\section{MATERIALS AND METHODS}

\section{Organism.}

A stock culture of $A$. fumigatus strain $\mathrm{N}-1$, isolated from sputum of a patient with pulmonary aspergillosis and maintained on Sabouraud's glucose agar at $27^{\circ} \mathrm{C}$, was used.

Culture media.

The basal sporulating medium was the modification of Sabouraud's agar ( $\mathrm{pH}$ 5.4-5.6), containing $1 \%$ Polypepton (Daigo Eiyokagaku Co., Ltd.) and 1\% glucose.

Unless otherwise indicated, Sabouraud's broth was used to determine the viability of the heated conidia.

Preparation of spore suspension.

A dormant spore suspension prepared from a slant culture of the fungus was spread uniformly on to a sporulating medium and incubated at $27-37^{\circ} \mathrm{C}$ for $4-7$ days. Ungerminated conidia developing on aerial hyphae of the fungus were harvested by floating on sterile distilled water. $\mathrm{T}_{\mathrm{c}}$ remove spore clumps and contaminating short hyphae, the spore harvests were filtered through a sterile paper filter (No. 5A, Toyo Roshi Co., Ltd.), otherwise the unfiltered spore suspension showed considerable variations in the thermal tolerance. Conidiospores were then washed twice with sterile $M / 15$ phosphate buffer (pH 7.0) by centrifugation and resuspended in it. The spore suspensions were standardized by cell number determined with a Thoma haemocytometer and diluted with phosphate buffer so as to contain a definite number of spores. The stock suspensions were stored in the refrigerator for not more than 7 days. Determination of heat resistance.

A water-bath equipped with an electric thermostat and a stirrer was used for heat processing. The 
pyrex test tubes containing the conidia were placed directly into the bath which was kept at the desired heating temperature. One $\mathrm{ml}$ of the standardized spore suspensions was pipetted into test tubes having an inside diameter of $18 \mathrm{~mm}$, a length of $180 \mathrm{~mm}$, and a thickness of $1 \mathrm{~mm} ; 4$ tubes were used for each heating interval when the heating increments were 5 min or less. After heating, the tubes were cooled quickly with running water. Ten $\mathrm{ml}$ of the recovery culture medium (Sabouraud's broth) was poured into each heated tube and incubated for 2 weeks at $27^{\circ} \mathrm{C}$. Growth as observed every 48 hours was examined carefully. Time of heating at a given temperature which is enough to produce no growth of conidia in any of 4 tubes was designated the thermal death time.

Table 1 presents an example of the thermal resistance data obtained with spore suspension of $A$. fumigatus by 4-tube technique. Our experience has shown that replicated determination by single tube technique often provides data exhibiting considerable variation. For example, the 2nd and 3rd columns at 7 days of subculture in Table 1 show the "skips" in case of 1-tube method and difference in the thermal death time may be observed in the results between 1st and 2 nd column at 14 days of recovery culture.

Table 1 Results of heat-resistance of $A$. fumigatus conidia by 4-tube method

\begin{tabular}{|c|c|c|c|c|c|c|c|c|c|c|c|c|c|}
\hline \multirow{3}{*}{ 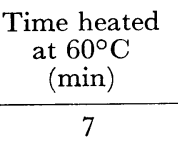 } & \multicolumn{13}{|c|}{ days of subculture } \\
\hline & \multicolumn{3}{|c|}{3} & \multicolumn{3}{|c|}{5} & \multicolumn{3}{|c|}{7} & \multicolumn{2}{|r|}{10} & \multicolumn{2}{|r|}{14} \\
\hline & + & - & + & + & +- & + & + & ++ & + & + & +++ & + & $++t$ \\
\hline 8 & - & ++ & - & + & ++ & - & + & ++ & + & + & +++ & + & $++t$ \\
\hline 9 & - & - & + & + & +- & - & + & +- & + & + & +++ & + & $++t$ \\
\hline 10 & - & - & - & + & -+ & - & + & -+ & + & + & +++ & + & $++t$ \\
\hline 12 & - & - & - & - & +- & - & - & +- & - & - & +++ & - & $+t+$ \\
\hline 14 & - & - & - & - & - & - & - & - & - & - & --- & - & -- \\
\hline 16 & - & - & - & - & - & - & - & - & - & - & --- & - & -- \\
\hline
\end{tabular}

Experimental conditions:

Spore age, 4-day-old on Sabouraud's agar; temperature of conidiation, $27^{\circ} \mathrm{C} ; \mathrm{pH}$ of suspending medium

(phosphate buffer solution), 7.0; spore concentration, 10 millions per $\mathrm{ml}$.

$+=$ positive growth

$-=$ no growth

Conidia were killed off by 5 -min exposure to $70^{\circ} \mathrm{C}$, but survived more than 3 hours at $50^{\circ} \mathrm{C}$.

\section{RESULTS}

\section{Effect of Concentrations of Spore Suspension}

Different densities of conidiospores produced on Sabouraud's agar were first tested for their heat resistance. Table 2 indicates that the greater the density of the conidia within the limits examined, the greater is the heat resistance of the conidia. However, a lower density of the spores (less than $10^{7}$ cells per $\mathrm{ml}$ ) showed the same thermal tolerance; they survived equally $12 \mathrm{~min}$ at $60^{\circ} \mathrm{C}$. For this reason spore suspension containing $10^{7} \mathrm{cell} / \mathrm{s} / \mathrm{ml}$ was standardized by means of a haemocytometer and used in the further experiments.

Effect of pH of Spore Suspending Medium

A. fumigatus conidia grown on Sabouraud's agar and washed in sterile deionized water were suspended in $\mathrm{M} / 15$ phosphate buffer solutions of various $\mathrm{pH}$ values. The thermal death time was determined by 
Table 2 Effect of concentrations of $A$. fumigatus conidia on their heat-resistance

\begin{tabular}{ccccc}
\hline \multicolumn{6}{c}{ survival time at $60^{\circ} \mathrm{C}(\mathrm{min})$} \\
\hline \multicolumn{6}{c}{ number of conidia $\left(\times 10^{6} / \mathrm{ml}\right)$} \\
\hline $1 / 10$ & 1 & 10 & 50 & 100 \\
\hline 12 & 12 & 12 & 14 & 18 \\
\hline
\end{tabular}

Experimental conditions:

Spore age, 4-day-old on Sabouraud's agar; temperature at which spores were formed, $27^{\circ} \mathrm{C} ; \mathrm{pH}$ of suspending medium $(\mathrm{M} / 15$ phosphate buffer), 7.0.

Table 3 Effect of $\mathrm{pH}$ of suspending medium on heat-resistance of A. fumigatus conidia

\begin{tabular}{cccccc}
\hline \multirow{2}{*}{$\begin{array}{c}\text { Survival time } \\
\text { at } 60^{\circ} \mathrm{C} \\
(\mathrm{min})\end{array}$} & 4.5 & 5.9 & 7.0 & 7.7 & 8.3 \\
\cline { 2 - 6 } & 12 & 12 & 12 & 16 & 16 \\
alive & 14 & 14 & 14 & 18 & 18 \\
dead & & \multicolumn{5}{c}{$\mathrm{pH}$ of suspending medium } \\
\hline
\end{tabular}

Experimental conditions are all the same as those described in Table 1, except for the $\mathrm{pH}$ of spore suspending medium.

the same manner as described above. The data shown in Table 3 reach the conclusion that $A$. fumigatus conidia may survive rather longer in the alkaline solutions at $\mathrm{pH} 7.7-8.3$ than in the neutral to acidic $\mathrm{pH}$ range (7.0-4.5), but there is no difference in the thermal tolerance.

\section{Effect of Temperature for Spore Formation}

Experiments were conducted to investigate whether the thermal resistance of $A$. fumigatus spores is influenced by the temperature of sporulation. For this purpose 4 different temperatures from 23 through 27,30 , and $37^{\circ} \mathrm{C}$ were used. As shown in Table 4, the conidiospores grown at $37^{\circ} \mathrm{C}$ survived $60 \mathrm{~min}$ at $60^{\circ} \mathrm{C}$, while those grown at lower temperatures of 23,27 , and $30^{\circ} \mathrm{C}$ survived only $12 \mathrm{~min}$. These results suggest that conidia formed at $37^{\circ} \mathrm{C}$ are more heat-stable than those formed at lower temperature.

Table 4 Effect of temperature of conidiation on heat-resistance of A. fumigatus conidia

\begin{tabular}{ccccc}
\hline \multirow{2}{*}{$\begin{array}{c}\text { Survival time } \\
\text { at } 60^{\circ} \mathrm{C} \\
(\min )\end{array}$} & $23^{\circ} \mathrm{C}$ & $\begin{array}{c}\text { temperature of conidiation } \\
27^{\circ} \mathrm{C}\end{array}$ & $30^{\circ} \mathrm{C}$ & $37^{\circ} \mathrm{C}$ \\
\hline alive & 12 & 12 & 12 & 60 \\
dead & 14 & 14 & 14 & 70 \\
\hline
\end{tabular}

Experimental conditions are all the same as those described in Table 1, except for the temperature at which conidia were formed. 


\section{Effect of Age of Conidiospores}

Strain N-1 of A. fumigatus employed in this study usually begins to yield conidia on Sabouraud's agar after 40 hours of incubation. Thereafter, maturation of the spores may proceed progressively; the temperature of spore formation gives a considerable effect upon the maturity rate of the spores. Table 5 indicates the relationship between the thermal tolerance of the conidia and their age when conidiation occurs at 27 and $37^{\circ} \mathrm{C}$. The most heat stable conidia were obtained from a 4- to 7-day old culture keeped at $37^{\circ} \mathrm{C}$. They survived $60 \mathrm{~min}$ at $60^{\circ} \mathrm{C}$. The older conidia of $10-21$ days of age rather decreased in the resistance.

Table 5 Effect of spore age on heat-resistance of $A$. fumigatus conidiospores

\begin{tabular}{ccccccc}
\hline \multirow{2}{*}{$\begin{array}{c}\text { Temperature } \\
\text { of } \\
\text { sporulation }\end{array}$} & $\begin{array}{c}\text { Survival time } \\
\text { at } 60^{\circ} \mathrm{C} \\
(\mathrm{min})\end{array}$ & 4 & 7 & 10 & 14 & 21 \\
\cline { 3 - 7 } & alive & 60 & 60 & 30 & 30 & 30 \\
& dead & 70 & 70 & 40 & 40 & 40 \\
\hline $27^{\circ} \mathrm{C}$ & alive & 12 & 40 & 20 & 12 & 12 \\
& dead & 14 & 50 & 25 & 14 & 14 \\
\hline
\end{tabular}

Experimental conditions:

Spore concentration, 10 millions per $\mathrm{ml}$; $\mathrm{pH}$ of suspending medium (phosphate buffer solution), 7.0.

The heat resistance of spores grown at $27^{\circ} \mathrm{C}$ was somewhat lower throughout their whole age than spores grown at $37^{\circ} \mathrm{C}$. The young conidia of 4-day age were the least resistant to heat at $60^{\circ} \mathrm{C}$. However, the matured conidia obtained from a 7-day old culture showed a marked increase in the heat resistance. They survived $40 \mathrm{~min}$ at $60^{\circ} \mathrm{C}$.

It is noted from the results obtained above that the temperature of conidiation and the age of conidia are of important factors which are directly concerned with their heat resistance.

\section{Effect of Sporulating Medium}

For the purpose of studying the variations in the heat resistance of $A$. fumigatus conidia ascribed to the kind of conidiating medium, the conidia were grown on (1) malt extract agar, with $1 \%$ glucose,

Table 6 Effect of the kind of conidiating media on heatresistance of $A$. fumigatus conidia

\begin{tabular}{lcc}
\hline & \multicolumn{2}{c}{ survival time at $60^{\circ} \mathrm{C}(\mathrm{min})$} \\
\cline { 2 - 3 } Conidiating medium & alive & dead \\
\hline Sabouraud's glucose agar & 60 & 70 \\
malt extract agar & 60 & 70 \\
soil extract agar & 45 & 50 \\
Czapek's agar & 70 & 80 \\
\hline
\end{tabular}

Experimental conditions:

Spore age, 5-day-old; temperature of conidiation, $37^{\circ} \mathrm{C}$; spore concentration, 10 millions per $\mathrm{ml} ; \mathrm{pH}$ of suspending medium (phosphate buffer solution), 7.0. 
(2) soil extract agar plus 1\% glucose, (3) Czapek's agar supplemented with $0.5 \%$ peptone, and (4) Sabouraud's agar as the reference medium. All media were adjusted to $\mathrm{pH} 6.0$ and incubation was $37^{\circ} \mathrm{C}$ for 5 days. Table 6 summarizes the results of heat-stability of spore crops produced on each sporulating medium. There was no remarkable difference in heat resistance among spores produced on these media. The conidia grown on soil extract agar, which may be regarded as being poor in certain organic constituents, were of slightly lower resistance than those grown on the other media.

Differences in Heat Resistance of Conidia of A. fumigatus Deu to Its Strains

Eight strains of $A$. fumigatus of different sources have been cultivated on Czapek's agar at different temperatures, and the resistance to heat of the conidia harvested from each culture compared. As indicated in Table 7, the strains were of unequal heat resistance, and the degree of the responses to increased temperature likewise were unequal. However, most strains were revealed to increase resistance with increasing temperature at which conidia were formed. Also, there was no evidence suggesting that the conidia of the strains isolated from clinical sources, e.g., sputum and lung, have an extremely high resistance.

The mature conidia of all strains grown at $37^{\circ} \mathrm{C}$ survived 60 min or more at $60^{\circ} \mathrm{C}$.

Table 7 Differences in heat-resistance of conidia of $A$. fumigatus due to its strains

\begin{tabular}{|c|c|c|c|c|c|}
\hline \multirow[b]{4}{*}{ Strain } & \multirow[b]{4}{*}{ Source } & \multicolumn{4}{|c|}{ survival time at $60^{\circ} \mathrm{C}(\mathrm{min})$} \\
\hline & & \multicolumn{4}{|c|}{ temperature of spore formation and spore age } \\
\hline & & \multicolumn{2}{|c|}{ at $27^{\circ} \mathrm{C}$ for 7 days } & \multicolumn{2}{|c|}{ at $37^{\circ} \mathrm{C}$ for 4 days } \\
\hline & & alive & dead & alive & dead \\
\hline N-1 & sputum & 40 & 45 & 70 & 80 \\
\hline $\mathrm{N}-2$ & sputum & 90 & 120 & 90 & 120 \\
\hline $\mathrm{N}-3$ & sputum & 80 & 90 & 120 & $?$ \\
\hline $0-3-1$ & lung & 70 & 80 & 70 & 80 \\
\hline $111-5-3$ & lung & 90 & 120 & 90 & 120 \\
\hline NHL-5009 & rice & 35 & 40 & 60 & 70 \\
\hline IFO 4399 & soil & 90 & 120 & 90 & 120 \\
\hline IFO 4400 & soil & 70 & 80 & 120 & ? \\
\hline
\end{tabular}

Experimental conditions :

Spore concentration, 10 millions per ml, heated in phosphate buffer solution $(\mathrm{pH}$

7.0) at $60^{\circ} \mathrm{C}$; conidiating medium, Czapek's agar plus $0.5 \%$ peptone.

? not examined more than 120 minutes

\section{Heat Resistance of Conidiospores of Several Aspergilli}

It was noted from the foregoing results that the mature conidia of A. fumigatus are considerably resistant to heat; they may resist moist heat at $60^{\circ} \mathrm{C}$ for an hour or more. To confirm whether this resistance is peculiar only to the spores of the fungus, a comparative study was undertaken with 7 species of Aspergillus group. Spore suspensions were not standardized by cell number, but by cell density represented by optical absorbency with a spectrophotometer, because of differences in spore sizes between different species of Aspergilli. Heat experiments were repeated 3 times to insure the accuracy of the data recorded. As is evident from the data of Table 8, the mature conidia of $A$. fumigatus have a far higher 
Table 8 Heat-resistance of conidiospores of several Aspergilli

\begin{tabular}{|c|c|c|c|c|}
\hline \multirow[b]{4}{*}{ Species and strain } & \multicolumn{4}{|c|}{ survival time at $60^{\circ} \mathrm{C}(\mathrm{min})$} \\
\hline & \multicolumn{4}{|c|}{ temperature of spore formation and spore age } \\
\hline & \multicolumn{2}{|c|}{ at $27^{\circ} \mathrm{C}$ for 7 days } & \multicolumn{2}{|c|}{ at $37^{\circ} \mathrm{C}$ for 4 days } \\
\hline & alive & dead & alive & dead \\
\hline A. flavus, IFO 6343 & 5 & 6 & 6 & 7 \\
\hline A. fumigatus, $\mathrm{N}-1$ & 40 & 45 & 70 & 80 \\
\hline A. nidulans, $\mathrm{T}-1$ & 3 & 4 & 5 & 6 \\
\hline A. niger, $\mathrm{N}-1$ & 3 & 4 & 7 & 8 \\
\hline A. sydowi, IFO 7531 & 2 & 3 & 2 & 3 \\
\hline A. tamarii, IFO 7465 & 7 & 8 & 6 & 7 \\
\hline A. terreus, IFO 6123 & 12 & 14 & 16 & 18 \\
\hline \multicolumn{5}{|c|}{$\begin{array}{l}\text { The concentration of conidiospores was standardized by optical } \\
\text { absorbency with a spectrophotometer at } 600 \mathrm{~m} \mu \text { wavelength and was } \\
\text { adjusted with additional neutral phosphate buffer so as to obtain a final } \\
\text { optical density of } 0.14 \text { at which the spore suspension of } A \text {. fumigatus con- } \\
\text { tained } 10 \text { millions cells per ml. Czapek's agar plus } 0.5 \% \text { peptone was used } \\
\text { for conidiation. }\end{array}$} \\
\hline
\end{tabular}

heat-stability than those of other Aspergilli. This fact leads to the conclusion that the conidia of A. fumigatus only have the ability to survive heat treatment which may kill off the conidia of other Aspergillus species within $10 \mathrm{~min}$ at $60^{\circ} \mathrm{C}$.

Changes in Heat Resistance of A. fumigatus Conidia during Germination

Germinants were obtained by inoculating dormant conidia which have a high resistance to heat into Sabouraud's broth. After incubation at $27^{\circ} \mathrm{C}$ for 6-9 hours under shaking, the cells were collected by centrifugation and filtered through a sterile paper filter so as to separate the ungerminated conidia. Young germinants were harvested both by pouring $\mathrm{M} / 15$ neutral phosphate buffer on to the filter which retains germinants and by floating on it. The concentrations of germinants and conidia were standardized by optical absorbency with a spectrophotometer. Heat resistance of both cells was then compared in the same manner as described above. Data presented in Table 9 indicate a rapid loss of heat resistance of the conidia occurring during germination. The young germinants arising from the conidia were killed off by short exposure, less than $10 \mathrm{~min}$, to $60^{\circ} \mathrm{C}$.

Table 9 Changes in heat-resistance of $A$. fumigatus conidia during germination

\begin{tabular}{cccc}
\hline $\begin{array}{c}\text { Survival time } \\
\text { at } 60^{\circ} \mathrm{C} \\
(\mathrm{min})\end{array}$ & $\begin{array}{c}\text { Conidia 4-day-old } \\
\text { on Sabouraud's } \\
\text { glucose agar } \\
\text { at } 37^{\circ} \mathrm{C}\end{array}$ & $\begin{array}{c}\text { Germinant } 1 \\
\text { obtained by } \\
\text { incubating the } \\
\text { conidia for } 6 \\
\text { hours at } 30^{\circ} \mathrm{C}\end{array}$ & $\begin{array}{c}\text { Germinant } 2 \\
\text { obtained by } \\
\text { incubating the } \\
\text { conidia for } 9 \\
\text { hours at } 30^{\circ} \mathrm{C}\end{array}$ \\
\hline alive & 60 & 9 & 8 \\
dead & 70 & 10 & 9 \\
\hline
\end{tabular}

The concentration of conidia and germinants was standardized by the use of a spectrophotometer and adjusted to 0.14 optical density at $600 \mathrm{~m} \mu$ wavelength. 


\section{DISGUSSION}

Few reports have been published on the resistance of fungus spores to heat. Difficulties to obtain a great number of spores in a pure state considerably prevent the study of their physiology and biochemistry. Since Faul $(1930)^{1)}$ pointed out the susceptibility of conidiospores of Neurospora crassa to injury by heat, fungus spores, in general, have been considered as they have no heat resistance or little, if any, except for a certain type of species, i.e., ascospores of $N$. crassa $^{2) 3)}$. Recently, Tada4) found that conidia of $A$. fumigatus remained viable at $60^{\circ} \mathrm{C}$ for more than 3 hours. Kitamura, Suenaga \& Nishio ${ }^{5)}$ also reported that chlamydospores and macroconidia of Epidermophyton floccosum subjected to $55-60^{\circ} \mathrm{C}$ survived longer than vegetative hyphae. These results may be interpreted as indicating a part of the peculiar physicochemical aspects of fungus spores, which are different from parent hyphae. The previous publications, however, omitted any mention or illustration of the detailed experimental conditions and the factors affecting the heat-stability of fungus spores.

It is long known that $A$. fumigatus is thermotolerant and can grow and sporulate over a range of temperature of $25-50^{\circ} \mathrm{C}$. This temperature "resistance" also serves as a basis for its isolation and identification from clinical materials" ${ }^{6}$. Thus, resistance of $A$. fumigatus conidia to heat may be expected to a certain extent. In the present paper, the heat resistance of conidia of $A$. fumigatus grown under varying conidiating conditions have been investigated by 4 -tube method. Also, the resistance to heat of the conidia harvested from 6 other species of Aspergillus has been compared. It was suggested that only conidia of $A$. fumigatus strains show a notably high resistance to heat. Further, the heat resistance was influenced by the conditions of growth, age, and other factors. The age of conidia and the temperature of conidiation are two important factors which decide their heat-stability. However, it is assumed that these findings would have been more available if the data had been expressed in percent germination of conidia rather than visible growth. Observation of appearance of mycelial growth up to 2 weeks after heat treatments, in tubes that contained $10^{7}$ or more conidia, could be rather misleading. Even a single surviving conidium can germinate and produce visible growth in a few days after treatments. Therefore, quantitative data based on the percent germination of heated conidia will be required for the confirmation of heat resistance. A comparative and statistical study of the heat resistance by a certain parameter is now under way in the author's laboratory.

\section{SUMMARY}

The heat resistance of conidiospores of $A$. fumigatus grown under varying sporulating conditions has been studied. To obtain a reliable and reproducible result, spore clumps were removed by filtration through a sterile paper filter and thermal death time was determined by 4-tube method. Matured conidia of $A$. fumigatus formed at $37^{\circ} \mathrm{C}$ were of the highest heat tolerance among those produced by seven species of Aspergillus used. They survived heating for more than $60 \mathrm{~min}$ at $60^{\circ} \mathrm{C}$, whereas both their parent hyphae and the conidia of other Aspergillus species were killed off by less than 10-min exposure to $60^{\circ} \mathrm{C}$. The age of conidia and the temperature of conidiation were of two dominant factors which affect their heat resistance.

\section{ACKNOWLEDGEMENT}

The author is greatly indebted to Drs. T. Hasegawa and H. Kurata for providing some of the 
strains studied.

\section{REFERENGES}

1) Faull, A.F.: On the resistance of Neurospora crassa. Mycologia, 22, 288-303, 1930.

2) Lingappa, Y. \& Sussman, A.S.: Changes in the heat-resistance of ascospores of Neurospora upon germination. Amer. J. Bot., 46, 671678, 1959.

3) Mitchell, H.K.: Crossing over and gene conversion in Neurospora. In the chemical basis of heredity, McElroy, W.D. \& Glass, B. (Ed.), The Johns Hopkins Press, Baltimore, 1957.

4) Tada, M.: Drug resistance of the genus
Aspergillus isolated from the patient with pulmonary aspergilloma. Japan. J. Med. Mycol., 9, 37-47, 1968.

5) Kitamura, K., Suenaga, Y. \& Nishio, K.: Studies on the resistance of chlamydospores of Epidermophyton floccosum. Japan. J. Med. Mycol., 9, 195-196, 1968.

6) Emmons, C.W., Binford, C.H. \& Utz, J.P.: Medical Mycology, 204-214, Lea \& Febiger, Philadelphia, 1964. 